\title{
CONFIAR. CON.FIAR. CONFI(N)AR: A NARRATIVA COMO ESTRATÉGIA FORMATIVA ANTE AS RECENTES TRANSFORMAÇÕES SOCIAIS
}

- LUCIANA HADDAD FERREIRA

https:/ /orcid.org.0000-0002-8440-7347

Universidade Metodista de Piracicaba

MARISSOL PREZOTTO

https:/ /orcid.org.0000-0001-7403-3188

Instituto Brasileiro de Formação de Educadores

JULIANA TERRA

https:/ /orcid.org.0000-0002-9303-9945

Secretaria Estadual de Educação de São Paul

RESUMO Considerando as recentes transformações sociais vivenciadas em todo o mundo, direcionando o olhar especialmente para os desafios impostos à comunidade docente em nosso país, apresentamos neste ensaio excertos de duas narrativas autobiográficas, escritas por nós no decorrer do isolamento social. Por meio delas, pretendemos discorrer sobre a potência da escrita narrativa como recurso formativo que se funda no fazer cotidiano, artesanal e coletivo. 0 texto também é construído narrativamente, em diálogo com os recortes e com autores que nos ajudam a pensar o tema, especialmente do campo da formação continuada e da filosofia da linguagem. Apontamos que diante do sentimento de solidão, em seus diversos sentidos, vivenciado intensamente na atualidade, a escrita narrativa se delineia como possibilidade de desenvolvimento do pensamento (por sua articulação com a linguagem) e da consciência (pelos excedentes de visão oferecidos). Também reafirmamos o movimento da escrita como ato ético e estético, de conexão com os pares e com o meio. Nesse sentido, destacamos o ato de narrar como dialético, constituído de ausências e presenças, ruptura e tradição. Sobretudo, como forma de resistência.

Palavras-chave: Narrativa autobiográfica. Formação docente continuada. Isolamento social. Solidão. Formação de professores. 


\section{TRANSFORMATIONS}

Considering the recent social transformations experienced around the world, focusing especially on the challenges imposed on the teaching community in our country, we present in this essay excerpts from two autobiographical narratives, written by us in the course of social isolation. Through them, we intend to discuss the power of narrative writing as a formative resource that is based on everyday, artisanal and collective making. The text is also constructed narratively, in dialogue with the clippings and with authors who help us to think about the theme, especially in the field of continuing education and the philosophy of language. We point out that given the feeling of loneliness, in its various senses, experienced intensely today, narrative writing is outlined as a possibility for the development of thought (by its articulation with language) and consciousness (by the surplus of vision offered). We also reaffirm the movement of writing as an ethical and aesthetic act, connecting with peers and the environment. In this sense, we highlight the act of narrating as dialectical, consisting of absences and presences, rupture and tradition. Above all, as a form of resistance.

Keywords: Autobiographical narrative. Continuing teacher education. Social isolation; Loneliness. Teacher training.

\section{ESTRATEGIA FORMATIVA FRENTE A LAS RECIENTES TRANSFORMACIONES SOCIALES}

Teniendo en cuenta las recientes transformaciones sociales experimentadas en todo el mundo, centrándose especialmente en los desafios impuestos a la comunidad docente en nuestro país, presentamos en este ensayo extractos de dos narrativas autobiográficas, escritas por nosotros en el curso del aislamiento social. A través de ellos, tenemos la intención de discutir el poder de la escritura narrativa como un recurso formativo que se basa en la creación cotidiana, artesanal y colectiva. El texto también se construye narrativamente, en diálogo con los recortes y con los autores que nos ayudan a pensar sobre el tema, especialmente en el campo de la educación continua y la filosofía del lenguaje. Señalamos que ante la sensación de soledad, en sus diversos sentidos, intensamente experimentados hoy, la escritura narrativa se describe como una posibilidad para el 
desarrollo del pensamiento (a través de su articulación con el lenguaje) y la conciencia (por el excedente de visión ofrecido). También reafirmamos el movimiento de la escritura como un acto ético y estético, conectando con los compañeros y el medio ambiente. En este sentido, destacamos el acto de narrar como dialéctico, consistente en ausencias y presencias, ruptura y tradición. Sobre todo, como forma de resistencia.

Palabras clave: Narrativa autobiográfica. Formación continua del profesorado. Aislamiento social. Soledad. Formación de profesores.

\section{Reflexões introdutórias: a \\ formação docente e as recentes transformações sociais}

\author{
Que minha solidão me sirva de companhia \\ Que eu tenha a coragem de me enfrentar \\ Que eu saiba ficar com o nada \\ E mesmo assim me sentir \\ Como se estivesse plena de tudo.
}

(LISPECTOR, 1978)

A confiança na humanidade possivelmente nunca esteve tão estremecida e, ousamos dizer, talvez nunca tenha se feito mais importante. Em tempos de obscurantismo, faz-se necessário recobrar quais são as características que nos conectam como humanos. Porque sociais, somos capazes de nos organizar conjuntamente, de modo a dividir tarefas e tornar a vida possivel, abundante, próspera e mais longínqua. Por sermos também produtoras de cultura, destacamo-nos de outras formas de vida, demonstrando que nossa condição não precisa ser meramente reativa, nem adaptativa. Antecipamos situações, imaginamos o que nunca vivemos, criamos. Interagimos com o meio porque podemos nos compreender como parte dele, numa relação dialética. A consciência orienta o modo como nos constituímos do coletivo e por isso insistimos em deixar marcas, construir símbolos e signos que ensinem às próximas gerações nossos caminhos, memórias e escolhas. Como seres históricos, pos- suímos memória - a pessoal e a da espécie -, que nos permite compreender um mundo que não está acabado e nem tampouco foi criado por nós, mas que se realiza no encadeamento de ações humanas. Nas palavras de Paulo Freire (1986), o mundo está sendo. Neste constante refazer, comum à humanidade que é inacabada, transitória e diversa, é imprescindivel restabelecer a confiança naquilo que nos parece estrutural das relações humanas: somos capazes de pensar, conhecer e mudar, conscientemente. Somos muitos, e constituídos uns pelos outros. A educação, nesse sentido, se apresenta como importante instrumento de humanização e tomada de consciência desta nossa condição no mundo.

Desde o início do período de distanciamento social, deparei-me com situações a serem narradas sobre a rotina familiar, a docência e a escola, porém, o tempo urgia e a demanda de afazeres da escola sempre ganha prioridade. No entanto, continuam gravadas na memória essas experiências, singulares, que vão me constituindo como pessoa e a profissional que sou. Hoje consigo tempo para escrever alguns retalhos de memória.

Não tem como não me recordar de estar na sala de aula, lá pela metade de março de 2020, nos últimos dias antes do fechamento do prédio, $e$ 
já não ter alunos. O sentimento de solidão se concretizou. No isolamento não só físico, mas afetivo que se instaurou, aos poucos fui percebendo que poderia criar formas de me manter dialogando constantemente com outros professores e funcionários, assim como com os alunos, pelas plataformas digitais.

Vale a pena dizer que mesmo antes da pandemia eu já vinha utilizando tecnologias educacionais interativas para organizar o trabalho docente e desenvolvê-lo com os meus alunos de 5o ano. Mas, também quero dizer que, usar tais ferramentas presencialmente, no cotidiano da escola, foi muito diferente de usá-las à distância. Junto aos alunos, era possivel redirecionar as escolhas pelo diálogo constante, pelas trocas de olhares, pelo corpo que ali se encontrava e pelas necessidades que iam surgindo diante das estratégias partilhadas para percorrer o caminho, lado a lado (Marissol, junho de 2020).

Partindo das narrativas (auto)biográficas que se anuciam e escutam-se ao longo do texto, organizamos a escrita em forma de ensaio, dando destaque a dimensões da educação e formação no contexto pandêmico que delas emergem, em articulação e diálogo com o pensamento de autores que nos ajudam a compreender o vivido, especialmente do campo da formação continuada e da filosofia da linguagem.

Confiar. Como professoras, nos tempos atuais, a confiança em nosso próprio trabalho e nos pressupostos que nos são mais caros está abalada. Palavras como "real" e "virtual" se misturam e nos convidam a repensar conceitos: o trabalho realizado por meio de recursos virtuais não é real? Qual é a dimensão da realidade no trabalho docente? "Presencial" e "a distância" também parecem ganhar novos sentidos: não há presença nas interações e conectividades? Quantas vezes parecemos próximos fisicamente, mas estamos distantes ou ausentes no que tange aos nossos interesses, atenção e afeto? A educação escolar, tal como acreditamos e defendemos, não prescinde dos recursos tecnológicos, muito úteis e potentes em certos contextos, mas certamente não se reduz a eles. A educação que defendemos e acreditamos é questionada quando julgam ser possivel uma escola sem pele, sem cheiro, sem roda de conversa, sem encontro de corredor, sem conflitos nem conversas paralelas, sem ajuda entre pares, sem pátios, sem coletivo. Porque a somatória de pessoas num mesmo ambiente, físico ou remoto, não é um coletivo. Numa proposta educativa que individualiza e fragmenta, pautada numa lógica que não é a sua própria, a confiança no trabalho compartilhado, naquilo que há de humano e que humaniza, se perde. Se não buscamos formas de instituir redes de partilha e nos fortalecermos como grupo, certamente parecerá estarmos ainda mais fragilizadas e sozinhas.

Con.fiar. Se em outros momentos já defendíamos a escrita narrativa como importante recurso de formação e estudo dos/com/para professores (FERREIRA, 2014; PREZOTTO, 2015; PREZOTTO, FERREIRA e ARAGÃO, 2015; TERRA, ANTONIO e PRADO, 2017; ARAGÃO; FERREIRA e PREZOTTO, 2017; PRADO et al, 2018), o contexto atual de isolamento social nos leva a pensar a prática narrativa pedagógica como forma de insistência no diálogo e na constituição de coletivos que se apoiem e se suportem mesmo a distância, em outras novas circularidades. Práticas de narrar exigem confiança, artesania e parceria. Há entrega de si ao outro, há um fazer por meio das palavras que é sensivel e se funda no compromisso de realizar a leitura do outro, na circularidade das experiências, na conexão com o que é humano. Ao tecer as histórias da docência em um modelo de educação pandêmico, os fios da vida da professo$\mathrm{ra}^{1}$ se entrelaçam aos da escola, das famílias, dos alunos. Fiamos com o outro, seja aquele que habita as narrativas contadas, sejam os

1 Escolhemos fazer referência ao coletivo docente no feminino, por serem as mulheres maioria em número e força de trabalho. 
interlocutores que a acessam, sejam aqueles que nos inspiram também com suas histórias. Recuperamos ou preservamos a prática de manter a palavra viva, fazendo com que certa circularidade exista, mesmo simbolicamente.

Confi(n)ar. Em momento de reclusão, testemunhamos uma situação de pandemia, vivemos a iminência da doença nos grupos mais próximos de contato. Não obstante, assistimos com estarrecimento as determinações políticas públicas nacionais que afirmam práticas ultraconservadoras e colocam em xeque os direitos sobretudo humanos. No âmbito da vida privada, lidamos com demandas domésticas, familiares e de trabalho como se o medo não existisse, como se o amanhã fosse certo e como se este fosse apenas um período suspenso das nossas vidas. Somado ao isolamento, vemo-nos confinadas nas próprias ideias, nos ciclos de trabalho mecanizados entre telas e janelas, presas num tempo que por vezes parece não contar; o mesmo tempo que nos acelera ao passar. É neste contexto confinado que Clarice, na epígrafe deste texto, convida-nos a encontrar diálogo e conforto na companhia de nós mesmas, das palavras dos autores que lemos. Tarefa dificil. Fazer da própria solidão, companheira. Nesse nosso movimento e pensamento, deparamo-nos com a dificuldade de narrar. Emudecemos.

Há dias decidi que escreveria sobre este momento, narraria alguma das muitas situações vivenciadas nessa condição pandêmica a que nos encontramos. Confesso que tentei iniciar várias vezes, mas as poucas palavras grafadas escureciam as páginas em branco. O celular, programado para despertar de madrugada, a fim de me fazer aproveitar o silêncio que ela traz, era reprogramado 3, 4, 5 vezes até que eu me deixava voltar para o sono em minha cama quente, ignorando o registro pretendido.

Hoje, parece que me dei conta dessa procrastinação e, mais ainda, dos motivos que me têm levado a ela. Sempre escrevi com prazer sobre minhas práticas pedagógicas e minhas sensibilidades docentes, falei sobre elas querendo ouvir meus parceiros nessa aventura da docência; mas, neste momento, minha relutância em transpor o que está dentro para o lado de fora é me arriscar em confirmar o sentimento de impotência, angústia e tristeza que me domina. Eu nunca me senti tão só e desesperançosa com a educação como agora, nesse momento pandêmico (Juliana, julho de 2020).

Se já lemos e ouvimos que a profissão docente é uma das mais solitárias (RUIVO, 2009), sabemos também que este sentimento remete a muitas compreensões. Como indivíduos, sentimo-nos sós porque não tem como olhar para o cenário político nacional e nos sentirmos minimamente representadas. A solidão, como docentes, decorre da falta de apoio e respaldo sociais, provenientes de políticas públicas educacionais que desqualificam nossa ação e nos retiram o domínio intelectual do próprio oficio. É, por vezes, um sentir-se só pelo abandono e desprestígio. Outras vezes, a solidão se manifesta em meio à multidão, quando nossos alunos - e aqui falamos de dezenas, geralmente três ou até quatro, a depender do contexto demonstram precisar da mediação qualificada da profissional e não há mais ninguém, não há mais braços para acolher, não há tempo para sanar todas as dúvidas. Ainda, a solidão brota da incompreensão com os tempos e movimentos da profissão, ante a negativa por diálogo, parceria e formação, na responsabilização da trabalhadora da educação pelo insucesso da escola, do cidadão, da vida em comum. Solitário também é o lugar de heroína que vez ou outra nos é atribuído e o qual insistimos em não aceitar, por entender que a metáfora cola na docente as piores representações: aquela que salva o mundo sozinha, que se abre mão de si, que é dotada de características que não são humanas e, sobretudo, que cumpre seu dever por vocação e chamado, não por excelência e reconhecimento profissional. 
Sentimo-nos sós embora nunca estejamos de fato sozinhas. Neste momento, a pandemia nos impele a provar outro sentimento de solidão: estamos fisicamente solitárias diante das telas, suscetiveis apenas às interações remotas. Desde o mês de março de 2020 até o momento de finalização da escrita deste artigo, em julho do mesmo ano, temos nos mantido isoladas fisicamente de pessoas da família, dos colegas de trabalho, do ambiente escolar, das atividades cotidianas - desde as mais simples, que nos davam pequenos prazeres, até as que nos tiravam a paciência e colocavam à prova a tolerância. Estamos sozinhas e aflitas, porém reafirmando a necessidade de mantermo-nos assim, distantes, já que até o momento essa ainda é a melhor e mais segura recomendação para preservar a vida de todos.

Mais do que antes, a narrativa, compartilhada com/para/entre professores, permite que nos associemos umas às outras, num dar as mãos que acolhe e solidariza. Reconhecemos nossas emoções, no sentimento do outro, através das palavras, trocas de experiências e das reflexões estabelecidas. Sabemos que muitas vezes partilhamos das mesmas dificuldades e angústias, das mesmas alegrias e conquistas. Dividir o que é vivido parece conferir humanidade e apoio mútuo, uma vez que estar sozinha neste momento não foi uma escolha. Podemos dizer que essa solidão é coletiva, também vivenciada em espaços-tempos diferentes na sociedade, e só parece ser diluída quando temos a capacidade de manter uma relação dialógica com o que vivemos, de modo a nutrir a esperança no que está por vir. Esperança que é verbo, como dizia Paulo Freire (1997), que nos mobiliza à luta por dias e condições melhores de trabalho, que se funda no pensamento crítico e na certeza de que somos mais capazes quando juntos.

Mas escrever não tem sido fácil. Temos aceitado e compreendido que há o tempo de calar e vivenciar, para que, então, seja possível narrar. Fomos acometidas, imaginamos que assim como outras professoras, por diferentes questionamentos, especialmente em relação à coerência daquilo que temos realizado como docentes, no contexto pandêmico, com o que anunciamos como premissas do trabalho docente. Nesta busca por referências, que nos recobrassem a perspectiva, algumas perguntas sempre voltavam a aparecer: quais são as possibilidades de criar e fazer circular narrativas pedagógicas, neste momento e espaço que vivemos? Como instituir práticas de diálogo e coletividade entre professoras, por meio da narrativa, diante do afastamento físico e isolamento social?

Por isso, reafirmando a potência da escrita narrativa, propomos neste texto uma reflexão das possibilidades do fazer narrativo docente, no contexto da pandemia que nos assola, como tessitura compartilhada. Essa escolha se justifica tanto pelo compromisso de fazer eco e trazer visibilidade à produção de professoras, quanto pelo entendimento de que é necessário e urgente discutir as possibilidades e espaços para a formação docente continuada nos moldes que se apresentam na atualidade. A narrativa também possibilita algo que temos como valor e princípio, o desenvolvimento da autonomia docente, tão bem traduzida nas palavras de Libâneo (2006):

[...] significa a capacidade das pessoas e dos grupos para a livre determinação de si próprios, isto é, para a condução da própria vida. Como a autonomia opõe-se às formas autoritárias de tomada de decisão, sua realização concreta nas instituições dá-se pela participação na livre escolha de objetivos e processos de trabalho e na construção conjunta do ambiente de trabalho (LIBÂNEO, 2006, p. 329).

Dessa maneira, optamos por trazer trechos de duas narrativas autobiográficas, tecidas por duas de nós, autoras, pes- 
quisadoras e professoras, com intuito de partilhar o vivido, pois acreditamos que podemos olhar para as situações cotidianas, organizadas em texto, e possibilitar a reflexão e conexão com outras tantas histórias e memórias. Dentre todo o material que vem sendo por nós produzido neste período pandêmico, fizemos escolhas que possibilitassem o desenvolvimento do tema aqui trazido para debate. 0 recorte, sempre necessário para que evidenciemos o que se mostrou potente, aponta para excertos das narrativas que escolhemos trazer. Com elas, a partir delas e sobre elas, discorremos sobre os efeitos e percepções do isolamento social no trabalho docente.

Cada um dos meus pensamentos, com seu conteúdo, é um ato singular responsável meu; é um dos atos de que se compõe a minha vida singular inteira como agir ininterrupto, porque a vida inteira na sua totalidade pode ser considerada como uma espécie de ato complexo: eu ajo com toda a minha vida, e cada ato singular e cada experiência que vivo são momentos do meu viver-agir (BAKHTIN, 2010, p. 44).

Este movimento de afastamento dos textos e de olhar de pesquisa é o que permite fazer escolhas e identificar o que é relevante para o estudo. Sabemos que não é necessário contemplar tudo, nem trazer muitos textos, uma vez que sua potência está no próprio ato de narrar e nos muitos sentidos e significados que cada escrita mobiliza. Assim como nos lembra Bakhtin (1920-24/2010), cada (narr)ação nossa remete a toda a vida, pois toda a vida se faz das nossas pequenas e singulares (narr) ações. A cada história contada, muitas outras narrativas são suscitadas: colaterais, entrecruzadas, transpassadas.
Narrativas docentes: estratégias de diálogo, resistência e formação

Além de orientar como e quando baixar e acessar o aplicativo para realização das aulas remotas, era preciso convencer os alunos a fazer uso do mesmo. Outras novas barreiras, colocadas além das telas que nos separavam: 'Dona, o professor da aula gravada fala muito rápido';

'Pró, eu queria anotar uma questão para te perguntar, mas não deu tempo, a imagem da tela mudou';

'Ah prô, preciso cuidar do meu irmão mais novo, não consigo assistir as aulas';

'Prô, aqui em casa é um barulho só. Muita gente gritando, é barulho de liquidificador, cachorro latindo, minha mãe brigando com minha irmã. Não consigo me concentrar';

'Dona, eu não estudava direito nem com você lá comigo na sala, brigando toda hora para eu prestar atenção, né? Como vou conseguir agora? Nem vou tentar'.

As falas, vindas dos meus alunos, entre tantas outras que surgiram em decorrência da aceitação (ou não) das aulas remotas, me traziam um importante excedente de visão. Eu entendia $e$ me reconhecia em cada fala. Eu também estava me sentindo perdida, desencorajada e fora do meu lugar. Também me faltava ânimo e atenção, assim como me faltava o combustivel maior para a minha docência: suas provocações, dúvidas e inquietações, como alunos. Mas era preciso continuar (Juliana, julho de 2020).

Juliana aponta na fala dos alunos, sobre seus impedimentos e dificuldades para a participação nas aulas remotas, dimensões importantes que embora não sejam vivenciadas por ela concretamente, a afetam. Ao nos identificarmos com as dificuldades e elaborações alheias, assim como coloca Bakhtin (1924/2000), assumimos o horizonte concreto desse outro, de forma que passamos a compreendê-lo e também a nos compreender me- 
Ihor, por extrairmos dessa relação aquilo que não conseguimos perceber individualmente. Assim como a professora, no diálogo e, especialmente, na escuta sensivel, saímos de nossa própria elaboração, conhecemos o mundo pela compreensão do outro para, em seguida, voltarmos a nós mesmas recuperando o próprio lugar. Por isso, considerar a presença marcante da narrativa e do diálogo para nossa constituição parece tão potente. Ao conhecer a dimensão do sentimento, da prática e do pensamento das outras pessoas, tomamos para nós, mas não o fazemos sem antes elaborar, conflitar com nossas próprias experiências e vivências. Diante desse encontro, pensamos as nossas próprias questões a partir dos planos ético e estético. No nosso olhar para o outro, naquilo que se produz nesta relação, criamos simbolizações, sentidos e marcas para nosso modo de ser no mundo. Dessa forma, o processo de identificação proporciona um princípio de completude e acabamento do outro que não acontece necessariamente em uma sequência cronológica (BAKHTIN, 2000, p. 47). Por isso, o relatado nos afeta em relação àquilo que pode ter sido vivido em outro tempo e se configura como memória, ou nossas perspectivas futuras.

A professora remete, em sua narrativa, ao termo bakhtiniano "excedente de visão". Tal menção nos leva à compreensão daquilo que é defendido por esse autor como a possibilidade que temos de ver o outro por ângulos e perspectivas que nunca teremos de nós mesmos, devido à posição exterior que ocupamos em relação às outras pessoas, que nos permite movimento, análise de contexto e de contrastes. Em relação à nossa ação, só podemos compreendê-la a partir de própria posição. Bakhtin (2000, p. 44) afirma que o excedente de visão, com relação ao outro, instaura uma esfera particular da nossa atividade, isto é, um conjunto de atos internos ou externos que só nós mesmas podemos pré-formar a respeito desse outro e que o completam justamente onde ele não pode completar-se. Enfim, olhamos e somos olhadas de um lugar, de um tempo e com valores diferentes; vemos no outro mais do que o próprio consegue ver e assumimos que as pessoas com as quais nos relacionamos enxergam em nós, e na vida que compartilhamos, coisas que não somos capazes de entender sozinhas. Quando alguém atribui a outro seu excedente de visão, permite-lhe completar-se como sujeito naquilo que sua individualidade não conseguiria (PREZOTTO, 2015, p. 156).

Compreendemos a narrativa como uma forma de oferecer à comunidade docente diferentes leituras da realidade, trazendo excedente de visão acerca da profissão e das relações vivenciadas no chão da escola. É aprender com o outro, no exercício de síntese a partir do que nos constitui e daquilo que conhecemos por meio da experiência humana.

Optei por não realizar atividades síncronas com meus alunos. Embora eu esteja disponivel a eles via aplicativos durante todo o tempo (muitas vezes atendo cada um deles fora do horário de expediente), minha estratégia foi de realizar contatos individuais. Temi criar nova fonte de exclusão. As falas dos meus alunos me eram caras, e claras. Eu não podia pensar em qualquer alternativa que tomasse o grupo sem considerar as subjetividades do modo como cada um vem atravessando este momento. Como acessar minhas aulas com horário marcado, se há um celular para todos os integrantes da família compartilharem? Como conseguiríamos nos ver no horário agendado se, para certo aluno, os estudos aconteciam de madrugada, quando o silêncio da casa permitia? Ou ainda, como ter horário marcado se os deveres da casa impostos pelos parentes próximos (pai, mãe, avó) aconteceriam no mesmo horário? Confesso que temi me frustrar na realização desses encontros, e de buscar culpados. Quis poupar a mim e a eles de mais um afazer na rotina já tão apertada. (Juliana, julho de 2020) 
Nesse momento de adaptações, sabemos que os dilemas cotidianos parecem tantos, e tão complexos, que boa parte de nosso fazer pedagógico deixou de se dar na realização da aula, junto aos alunos, para centrar esforços nos meios pelos quais isso pode vir a ser possivel. Dada a urgência em oferecer apoio e se fazer presente na vida dos alunos e famílias em meio ao caos que se instaura, cada profissional tem buscado ferramentas e estratégias que considera adequadas para suas ações e para aqueles que estarão consigo nesse processo. Em comum, percebemos o sentimento de preocupação com a comunidade escolar e a certeza de que neste momento, seria inconcebível que nada fizéssemos e simplesmente nos retirássemos da vida dos alunos. Ainda, vemos as ressonâncias do trabalho coletivo e compartilhado, instaurado no antes, e que sustenta as relações neste durante: assim como apontam Ferreira e Barbosa (2020), por meio das redes sociais e de plataformas de comunicação, aquelas que entendem mais de certa ferramenta, oferecem ajuda a quem tem pouca familiaridade. As que dominam certas estratégias, dividem-nas com as recém-chegadas no universo digital.

No contexto de isolamento social a que fomos submetidas, narrar o que vivemos e fazer circular as reflexões que emergem das práticas cotidianas têm sido mais do que um recurso formativo. A escrita que emancipa e reafirma princípios tem possibilitado o diálogo e a parceria ao proporcionar encontros e conexões entre profissionais que não possuem mais o chão da escola para realizar tais trocas, que não contam mais com as conversas de corredores, as trocas de sala de professores, os pedidos de ajuda e interlocução tão comuns nas brechas do cotidiano.

Mesmo emudecidas, num momento inicial de torpor diante a toda a aridez que temos vivido e presenciado diariamente, insistimos no exercício de narrar como vital. Se defendemos a pertinência da elaboração de narrativas pedagógicas como estratégia formativa no contexto pandêmico que vivemos, o fazemos na certeza de que este modo de conceber a formação continuada possibilita a emancipação das professoras e a busca por caminhos e respostas que thes sejam próprias. Como afirma Nóvoa (1998), a identidade docente pode ser pensada não como um dado adquirido, uma propriedade, um produto, mas como um processo. No contato com a comunidade educativa, as professoras intencionalmente articulam o seu pensar e o seu agir, criando maneiras próprias de lidar com o oficio, sem reproduzir práticas ou soluções prontas.

Defendemos no presente trabalho a narrativa como produção autoral docente porque quando escrevemos sobre o que acontece e como nos sentimos, elegemos fatos, articulamos e reordenamos, considerando aquele que nos lê. Ainda, mantemos na escrita a contradição, mostrando que os inesperados nos desestabilizam e dão sentido ao que vemos e somos.

Foi aqui o meu pulo do gato. Escutei a mim mesma e o que as falas das crianças traziam, inclusive o silêncio de vários. Parei o tempo presente $e$, mesmo sem ter outros indícios mais visiveis da sala de aula - gestos, olhares, emoções -, fui buscando ouvir e ler nas entrelinhas o momento, sem julgamentos para que pudesse dali externalizar toda a delicadeza possivel para construirmos juntos um novo caminhar de uma escola que está sendo descoberta e explorada para além do que imaginávamos quando iniciamos o ano letivo em janeiro de 2020 (Marissol, junho de 2020).

Quando Marissol se refere à importância da escuta, chama a nossa atenção também para a importância das palavras, ditas ou grafadas, para a constituição do nosso modo de pensar. Nesse sentido, concordamos com Vigotski (1934/2001) ao afirmar que a palavra tem papel determinante na formação do pen- 
samento, uma vez que são compreendidas como signos que medeiam a nossa relação com a cultura e o meio. É pela palavra que o pensamento se exprime, mas é também a palavra o elemento que o constitui. Existe assim uma relação fundamental entre pensamento e palavra, de modo que esta possibilita a formação do pensamento, tornando-o mais capaz de compreender o mundo e produzir novos signos, que por sua vez exprimem suas necessidades e desejos, interferindo na cultura e nos contextos vividos. Desse modo, apoiadas em Vigotski (2001), podemos afirmar que é a palavra das professoras, dita ou narrada, que constitui o pensamento e possibilita a criação de sentidos pessoais para a docência. A palavra, nessa perspectiva, não é anterior nem posterior ao pensar, pois ao dizer/escrever, o pensamento se realiza num processo sincrônico entre o desenvolvimento dos signos e das ideias. Pela fala, tornamo-nos capazes de organizar o pensamento, planejar nossas atitudes e antecipar ações futuras. Por intermédio da linguagem, podemos interpretar informações e mudar nossas ações de acordo com os novos fatos.

Reafirmamos que, nos fragmentos apresentados, nos aventuramos na escrita que nos possibilita organizar o pensamento, ao mesmo tempo que revela a miudeza do que ocorre nas atividades escolares e neste modo pandêmico de lidar com a educação, na busca por compreensões para nós mesmas e, ao mesmo tempo para a comunidade educativa. Nessa maneira de fazer, é possivel encontrarmos uma identidade narrativa, inacabada e por isso aberta, diversa, que nos desestabiliza e nos faz refletir sobre o que está posto nas/pelas palavras ou pelos sentidos que são evocados ao lê-los. As narrativas, ao serem lidas, provocam a escuta para além do que está escrito. Traz uma proximidade entre perguntar, pensar e responder, permitindo abrigar-se nas palavras que extravasa o texto e abre múltiplas possibilidades de caminhos.

Por ser atitude com/para o outro, a narrativa só faz sentido como escrita social e compartilhada. Precisamos dos interlocutores. Por isso, às vezes, o sentimento de solidão nos cala. Ao se ver só, sem o contato físico ou mesmo a presença remota dos alunos, Marissol se permite refletir sobre outras experiências que suscitaram os mesmos sentimentos, em outros tempos. Na solidão, busca interlocutores e, assim, não deixa de narrar.

Neste movimento de voltar a si, fui eu revisitar alguns guardados e deparei-me com memórias e com uma questão que me acompanha faz certo tempo, desde a época que fui para Portugal, em 2011, para o aprofundamento dos estudos do Doutorado: o sentimento de solidão. Que solidão é essa? O que ela suscitava em mim naquele momento? Remexendo nos cadernos de anotações, relembro de leituras feitas e, penso que retomar alguns principios do trabalho compartilhado, que desenvolvi em minha tese de doutorado, se fez mais importante ainda.

Não podia ignorar esse sentimento de solidão que permeava a mim e a outras pessoas, a solidão que se revela na ausência de contato físico, porque a solidão do professor não me ocorria. Digo isso por entender que quando estamos na sala de aula (literalmente na sala de aula ou na tela do computador, que tem sido a sala de aula), nossa conexão de ideias e afetos faz lembrar que não estou assim tão só. Estou acompanhada de tantos outros professores, autores, pessoas que me compõem porque, ao pensar no planejamento da aula, no projeto a ser desenvolvido, convoco ali pessoas importantes que dialogam comigo e que me dão uma direção (Marissol, junho de 2020).

A partir das narrativas de Marissol e Juliana, elaboramos outras reflexões acerca da escrita que se funda nos fazeres, pensares e sentires cotidianos:

Narrar é ruptura (não se prende às amarras do texto formal, não pretende oferecer 
explicações). O momento de narrar faz com que possamos romper com o registro tradicional acadêmico, por vezes tão normatizado. Se a escrita convencional tende à isenção e suposta neutralidade daquele que escreve, a narrativa reafirma as marcas da subjetividade de quem fala, a autoria de quem colabora e os diálogos literários, poéticos, metafóricos e alegóricos que nos ajudam a pensar e compreender grandes questões. A licença estética se alia a forte componente ético, que faz com que a escrita deste gênero se alicerce em bases teóricas igualmente transgressoras, que defendam a importância dos processos, dos afetos, da forma em relação ao conteúdo. Nesse movimento, o texto ganha uma arquitetura própria e mostra a trajetória por nós realizada. Quando existe a organização das ideias pelo registro escrito, temos condições de nele vislumbrar nossas práticas e atuar sobre elas, sem precisar tecer explicações ou direcionar entendimentos. Como obra, é aberta e se completa no entendimento do outro.

Narrar é tradição (remete ao coletivo, dialógico, humano, histórico). Ao passo que carrega certo ar de novidade quanto à forma, a narrativa também é alicerçada na tradição quando a compreendemos como prática intergeracional de preservação e propagação de saberes. Contar histórias que trazem reflexões que podem ser importantes para as outras pessoas da mesma comunidade é uma atitude milenar e que se funda, nas palavras de Benjamin (1940/1994), na experiência coletiva da humanidade. As regras, nuances, entonações, sentimentos e relações registradas se pautam em uma forma socialmente difundida e aprendida, que permite a compreensão não dos detalhes da vivência narrada, mas sua estrutura central. Ainda, quando registramos por meio da narrativa, eternizamos situações vividas e ampliamos o repertório comum das docentes, que possibilita a compreensão de diferentes maneiras de trabalhar, organizar, refletir em um determinado sistema social. Dessa maneira, as práticas cotidianas se formalizam e procuram trazer as categorias sociais que compõem a história.

Narrar é ausência (a experiência narrada não é do narrador, ele é só o veículo). Por mais que cada história narrada remeta a algo concretamente vivenciado, aprendido ou apreendido, ao tecer a escrita pedagógica a professora narradora compreende que aquilo merece ser contado porque é parte da experiência social. Usando nossas vidas e interações como metáforas emprestadas, narramos o que é comum por ser histórico, que mobiliza nossa humanidade. Narramos o encontro, o vazio, o abraço, o cotidiano, as conquistas, a solidão. Assim, quando o texto é construído, dele nos ausentamos, retiramos nossas impressões e comoções pessoais e acentuamos o que pode ser potente para a experiência de leitura do outro. Nesse momento, ao nos fazermos ausentes, distanciamo-nos do vivido, passando a enxergar coisas que antes não éramos capazes de identificar. Desse lugar exotópico (BAKHTIN, 2010), novos sentidos vão sendo traçados ao exposto.

Narrar é presença (conecta gerações, tempos, espaços, experiências). Ao mesmo tempo que como narradoras somos ausência, também nos fazemos presença. Isso porque carregamos na escrita o olhar direcionado de quem viveu, sentiu e organizou as ideias a serem transmitidas na narrativa. Segundo Aguiar e Ferreira (2020, p. 13), “narramos o que julgamos relevante, colocamos nela nossas representações e expectativas, damos certa tônica ao relato". Paralelamente, a narrativa se torna influenciada pelo tempo cronológico, uma vez que ela traz em si a sequência de situações ocorridas em determinados espaço e momento e, portanto, ela se organiza na cronologia do tempo. E, esse momento, está 
inserido em certo contexto histórico, em espaços múltiplos, que influenciará o narrado. Ao nos propormos a narrar, o tempo se torna essencial no processo. Podemos afirmar que narrar é presença pois remete sempre ao momento em que se escreve, quando as memórias e recordações se atualizam, em confronto com as expectativas de alcance e diálogo com determinados interlocutores. É no agora que a escrita acontece.

Narrar é resistir (amplia a consciência de quem narra e de quem lê). Entendendo ser preciso reafirmar princípios e manter a coerência neste momento de tamanha exceção, optamos por também enfatizar as possibilidades transgressoras, de resistência e reexistência da narrativa. Dizemos isso por saber e reconhecer a urgência em apontar para as inúmeras dificuldades e enfrentamentos vividos, mas também por entender que a produção e circulação de saberes que reafirmam a potência da escola e do trabalho docente é igualmente necessária para sermos capazes de enxergar saídas.

Dizemos isso porque quando narramos, partilhamos também responsabilidades e nos tornamos mais conscientes e resistentes, pois mesmo na solidão do isolamento social, percebemos haver um coletivo que dialoga e se apoia. É importante olhar para aquilo que nos importa, aquilo que nos marca, aquilo que nos compõe, aquilo que nos constitui para que os valores que defendemos não se percam nesse caminho incerto.

Neste cruzamento dos tempos, na interseção entre narrador e locutor, a narrativa amplia seu potencial metodológico no contexto da pesquisa, uma vez que possibilita a construção de saberes e conhecimentos a partir das interpretações e compreensões possíveis, não apenas para o narrador, mas para quem se dispõe a realizar uma análise crítica do narrado; promovendo a clareza da constitutividade entre a teoria e a prática.
Eu, confesso, não temia as novidades tecnológicas, mas o novo tempo que me era imposto. Continuava formalmente trabalhando as mesmas horas por dia, porém agora era preciso conciliar simultaneamente meu papel de mãe, mulher e filha. O tempo, o 'mesmo tempo', parecia agora pouco para tantos afazeres. E, assim como a música 'Embolada do Tempo', de Alceu Valença, eu desejava parar o tempo, mesmo sabendo que ele não tem parada: 'Você quer parar o tempo / E o tempo não tem parada / Você quer parar o tempo / O tempo não tem parada' (Juliana, julho de 2020).

Juliana traz em suas palavras que o temor ante o novo formato de aulas, no contexto remoto, não era em relação à apropriação dos recursos educacionais, mas sim em relação ao acúmulo de exigências que a ocupam e tentam desviar seu olhar da organização do trabalho docente. A rotina cheia de protocolos invade ainda mais o seu espaço privado e se mistura aos afazeres de outros tempos. Dessa forma, mostra a constante tensão entre o tempo cronológico e o das relações, tempos que nos constituem. Lembramos de Benjamin (192740/2006), quando este diz que o tempo da história é o encontro intensivo de uma temporalidade não causal, mas intermitente. Irrompe-se com o tempo como repetição mecânica e abrese a possibilidade de uma experiência intensiva que é carregada de presenças. Quando Juliana traz a vontade de parar o tempo, está querendo suspender o tempo linear, mostrando sua resistência a esta lógica produtivista, como um posicionamento político. A professora insiste em estranhar uma cronologia que limita, amordaça e inviabiliza seu ofício. Com isso, traduz em palavras nosso sentimento de luta por uma docência que se funda na artesania, na reflexão e na escuta, pois é por meio dessas que possiveis revoluções podem ser construídas, tanto na esfera de nosso desenvolvimento pessoal quanto no campo da educação e da sociedade. 
É nesse ínterim que Juliana e tantas outras professoras, como nós, vão aprendendo a lidar com esse tempo atual, tão enfático e complexo. Assim como nos coloca Freire (1986), a atitude docente ante as mudanças sociais deve ser de criticidade e posicionamento, não de adaptabilidade dócil e ingênua:

Insistimos, em todo o corpo de nosso estudo, na integração e não na acomodação, como atividade da órbita puramente humana. A integração resulta da capacidade de ajusta-se à realidade acrescida da de transformá-la a que se junta a de optar, cuja nota fundamental é a criticidade. na medida em que o homem perde a capacidade de optar e vai sendo submetido a prescrições alheias que o minimizam e as suas decisões já não são mais suas, porque resultadas de comandos estranhos, já não se integra. Acomoda-se. Ajusta-se. 0 homem integrado é o homem sujeito. a adaptação é assim um conceito passivo - a integração, ativo (FREIRE, 1986, p. 42).

Este diálogo com o tempo, que marca a intencionalidade e consciência das professoras ao narrar, permite uma atuação propositiva e esperançosa, pois se funda numa visão concreta, realista daquilo que se vive, sem naturalizar ou romantizar tudo o que temos vivido, mas também lembrando que cada uma de nós constituímos o meio do qual fazemos parte e, por isso, podemos ousar e resistir, por meio de práticas emancipatórias e transgressoras. Assim como aponta Vigotski (1927/2018), o meio imediato no qual vivemos é determinante para nosso desenvolvimento pessoal e para a produção da cultura a que estamos imersas. No entanto, ao mesmo tempo em que tomamos da realidade elementos para nos compreendermos como professoras e pesquisadoras, também fazemos parte desta mesma realidade e nossa presença e atuação interferem no desenvolvimento e compreensão que se tem do meio. Assim, num movimento dialético e síncrono, a professora Juliana - tal como Ma- rissol também nos ensina em excerto a seguir - mostra que o estranhamento gera reflexão e busca por possibilidades.

O período de férias antecipadas, estipulado pela escola, e uns dias de feriado, antecipados pela cidade onde moro, foram vividos por mim com muita introspecção, para poder recarregar as energias, distanciar-me do que foi vivido no chão da escola, de modo que eu fosse então capaz de realizar novas escolhas. Pensar em alternativas, talvez nem tão novas, mas que pudessem ser redimensionadas no tempo, na forma de abordar, no jeito de organizar o que se vive do lado de cá da tela como professora e, do lado de lá, como educando.

Além da preocupação com a realização de trabalho, era de suma importância tentar encontrar algum equilíbrio entre o planejamento, sua realização e verificação, de modo que não houvesse uma grande sobrecarga de tarefas. Eu tentava me preservar ao máximo do desgaste fisico e emocional em decorrência desta mudança profissional tão brusca, pois como sujeito pertencente a essa sociedade, também vivenciei outras situações que já eram aflitivas, como a não visita dos pais que moram em outra cidade, a preocupação com as reações (ou não) do filho adolescente, os familiares que estão na linha de frente do COVID-19, a ausência dos amigos, o medo da perda (do espaço de trabalho, das pessoas que tanto amo, de mim mesma).

Percebi que esta tentativa de manter algum equilíbrio foi importante para os alunos e suas familias, que também estavam em outro contexto e reaprendendo a lidar com novas demandas (Marissol, junho de 2020).

0 registro de Marissol nos remete às palavras de Bakhtin (2000), ao defender que as ações docentes, quando esmiuçadas na narrativa, trazem à tona mais do que a situação, pois revelam as escolhas daquela que narra e o seu agir. No ato relatado, estão contidas suas reflexões e evidenciam concretamente um sujeito que age, um lugar em que se atua e um momento em que a ação ocorre. Ao mostrarmos tantas dimensões do ato, deixamos em 
evidência também o que o ato produz em nós mesmas e aquilo que por ele é desencadeado. Nessa relação de ir e vir, colocamo-nos concretamente em nossa humanidade.

Podemos também perceber que ao narrar, a professora vai nos apresentando como se dá a organização do trabalho docente para além do ato fisico de ordenar coisas, remetendo à ação como fazer também vinculado ao pensar e sentir, e potencializando as relações humanas ali presentes. Assim, tomamos o próprio narrar como ato e como jeito de com.par.t(r)ilhar ${ }^{2} 0$ que pensamos e como fazemos a docência.

\section{Lições aprendidas: da narrativa (auto)biográfica para a formação docente}

Diante do narrado, evidenciam-se dimensões do trabalho das professoras que são com.par.

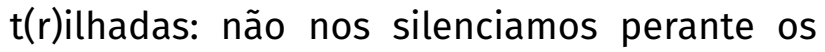
questionamentos, vivenciamos a reflexividade as questões cotidianas e desenvolvemos a nossa consciência enquanto indivíduos e classe. Queremos destacar que muitas vezes o sistema educacional vigente não considera as necessidades coletivas dos professores, independente do contexto atualmente vivenciado. Faz-se necessário pensar em políticas públicas que intencionalmente favoreçam o diálogo, a instituição de círculos de formação e que destinem tempo e espaços adequados para esta construção. Nesse sentido, Libâneo (2006) há muito nos alerta, dentre outros pesquisadores, sobre a importância de nos posicionarmos criticamente como categoria, em defesa da educação como área de conhecimento, campo de reconhecimento e luta por suas especificidades. Quando todos pensam ter algo a dizer em nome dos professores, os próprios profis-

2 O termo "com.par.t(r)ilhado" foi desenvolvido por Prezotto (2015), ao referir sobre a importância de estar com o outro na caminhada que se estabelece ao longo da formação docente. sionais se veem destituídos de seu saber, reduzidos à condição de executores de tarefas, o que jamais poderíamos aceitar, seja em nome da crença de que o trabalhador emancipado é aquele que conhece, pensa e domina seu oficio do início ao fim, seja em nome do princípio educativo mais central que temos defendido, o de que as teorias educacionais são produzidas, conflitadas e reafirmadas no cotidiano do trabalho docente.

Assim, sempre que uma narrativa nos convida a reolhar para o trabalho docente, percebemos nela refletida, importantes bandeiras e lutas que caracterizam como um trabalho com. par.t(r)ilhado e que têm sido essenciais na prática pedagógica em tempos de distanciamento/isolamento social.

Tendo explorado minimamente os recursos da plataforma interativa utilizada, fazia dias que eu estava querendo dar um passo além e propor algo que rompesse com a centralidade das minhas falas / das falas comigo / para mim. Organizei uma proposta de trabalho, conversei comigo mesma recuperando o que acredito $e$ partilhei com uma mãe, para ver o que achava. Fui lá e me arrisquei numa proposta na qual as crianças trabalhariam em duplas. Meu objetivo era que estivessem juntos e vivenciassem formações possiveis na sala de aula, novamente.

Ao avaliar o primeiro momento de trabalho em dupla com as crianças, reencontro a confiança para proporcionar outras ações que fizessem com que todos saíssem da zona de conforto. Ao conversar com alguns pais, após a aula, escutei:

- 'Eu confio em você, mas preciso te ver e ouvir para garantir que tudo está caminhando bem'.

- 'Foi tão bom o dia que você colocou os alunos para trabalhar juntos. $O$ brilho nos olhos $e$ a alegria de estar ali foram visiveis'.

Tudo saiu como planejado? Lógico que não. Tive que administrar, a distância e on-line, crianças que não tinham contatos uma das outras, algumas familias que tinham dificuldade para acessar a plataforma no horário de aula, a ansiedade de esperar pelo outro para realizar a 
atividade, a escrita colaborativa que ainda não tinham experimentado em classe, e a minha própria reflexão e curiosidade do que estava acontecendo.

Em dias que nem tudo dava assim tão certo, escutava de um aluno, em conversa privada, quando o questionado sobre uma atividade deixada em branco:

- 'Mari, você confia em mim? Eu fiz. Coloquei imagem e escrevi. Não sei o que aconteceu'.

De algo eu tinha certeza. Tinha que experimentar algo que acredito, que é estar com o outro e estar aberta ao diálogo, pois ao lançar mãos de diferentes ações para poder concretizar o trabalho proposto, eu ia transitando entre o que era possivel ter controle e o que não era. Nas brechas, fui vendo que as individualidades foram sendo trabalhadas e o coletivo foi sendo retomado, mesmo que estivéssemos cada um na própria casa, mas olhando pela janela para a escola e a vida (Marissol, junho de 2020).

Nessa relação dialógica, a professora revela a presença, a valorização e a confiança no outro. É com o outro que dialoga para compreender o que se passa ou que está por vir. É com o outro e com ela mesma que negocia constantemente o que precisa ser feito, quais as escolhas que têm que fazer e quais caminhos trilhar. Independente do caminho, revela que a relação ali estabelecida é repleta de afetividade. Destacamos, aqui, a ideia de afeto construída pelo ato: de se permitir afetar pelo outro, e por ele sermos afetadas, demonstrando percepção sensivel, respeito e responsabilidade com o fazer pedagógico.

As relações narradas e vivenciadas pelas professoras demonstram ser repletas de afeto pois se fundam numa intencionalidade que articula histórias, desejos e contradições da professora, dos seus alunos, das famílias e de toda a comunidade. Por assumir compromisso com uma educação que extrapola a mera transmissão passiva e fragmentada de conteúdos, a professora aproxima, conecta e hu- maniza as relações ao narrar e fazer circular suas escritas. Ela faz com que compreendamos que o distanciamento físico pode ser mantido, porque necessário e apenas enquanto é imprescindivel, pois descobrimos formas de nos mantermos afetivamente ligadas às relações nutridas no chão da escola.

Ao nos encontrarmos, mesmo que pelas telas, as entonações de voz, as marcas da escrita, as expressões faciais ganham outra dimensão, potencializam a afetividade e fazem com que as incertezas da vida ganhem uma certeza provisória - outro está ali. A narrativa de Marissol nos ensina que a amizade e a amorosidade presentes no cotidiano da escola, que muitas vezes parecem estar dormentes pela falta de nossa vida coletiva no chão da escola, se reinventam em outras formas de existir e se fazerem presentes.

Quando nos fazemos cúmplices e vivenciamos o espaço da escola com mais amorosidade, o tornamos diferente, pois imprimimos as marcas de nossa ética e estética às relações. Ao nos apoiarmos uns aos outros, podemos dar outro sentido ao que está sendo imposto e reinventar, tanto a situação quanto a nós mesmas. Na escrita de Marissol, é possível perceber que a confiança se faz ainda mais necessária para que possamos transitar e percorrer o caminho com respeito e cuidado. A confiança perante o caos instaurado faz que o outro estenda as mãos e, ao seu lado, participe ativamente deste momento. Esse tipo de relação se alicerça no diálogo, no trabalho coletivo e na formação cotidiana.

O telefone está vibrando novamente. Outra reunião extraordinária com a direção da escola me obriga a parar as reflexões nessa narrativa. A letra de uma música invade meu consciente e eu a entoo alguns versos antes de acessar o link da reunião:

'A gente vai contra a corrente Até não poder resistir 
Na volta do barco é que sente

o quanto deixou de cumprir

Faz tempo que a gente cultiva

A mais linda roseira que há

Mas eis que chega a roda-viva

E carrega a roseira pra lá'

(Juliana, julho de 2020).

Rocha e Sá-Chaves (2012) colocam que muitas escolas estão se tornando "sem alma", inertes, isto é, tem sido compostas por profissionais que já não estão motivados, que não contagiam uns aos outros (ou se contagiam), se tornando reprodutores e acríticos. Os medos e anseios do período de pandemia também permeiam professores e alunos. Por vezes tememos ceder à ideia de que estamos todas deslocadas da realidade, retiradas de nosso próprio espaço, do nosso lugar praticado, como nos diria Certeau (1994). O teletrabalho virou sobretrabalho. Às professoras e aos alunos não há tempo para recomposição da saúde física e mental. A existência do ser humano parece ter sido descartada.

Estamos todas suscetiveis ao adoecimento e ao mesmo tempo compreendemos que nossa atuação é definidora do modo como a sociedade poderá elaborar o que se vive: somos por vezes a referência e o filtro entre informações distorcidas e orientações confiáveis. Também nos vemos como parte de um grupo que propicia momentos de discussão e reflexão que extrapola o binômio pandemia $x$ crise econômica, oferecendo aos alunos algum respiro e equilíbrio para o enfrentamento das dificuldades cotidianas. Entendemos a gravidade do que é vivido e não nos resignamos nem ao lamento, muito menos à aceitação. Por isso, vemos na narrativa possibilidade de elaboração e proposição de fazeres que nos restituem a autoria e domínio do próprio trabalho, que possibilita o diálogo e a coletividade.

Confiar. As lições das narrativas não se restringem a este contexto pandêmico: o mo- mento de total exceção ampliou problemas que já discutíamos há tempos e que precisam ser encarados com urgência para que possamos construir um caminho outro na educação e na formação dos sujeitos que ali estão envolvidos. Con.fiar. Para fiar, tecer, enredar, criar tempos e espaços de artesanias, de fazer junto de manter não apenas o diálogo (também ele), mas também o desenvolvimento sensivel que nos foi tão bruscamente retirado, precisamos confiar. A confiança exige um clima de respeito e cuidado presente na relação vivida para que exponha suas ideias, medos, angústias, ações, valores sabendo que será respeitado. Ao partilhar, as professoras tecem com cuidado o seu percurso formativo possibilitando que outros se identifiquem ao que viveu, revelando o humano que ali está. Con.fi(n)ar. Diante da ausência do "velho cotidiano", surge a necessidade de criarmos novos espaços, outras redes que fortaleçam a classe docente e possibilitem a articulação de um coletivo que não feche os olhos aos problemas que enfrentamos, sem também deixar de assumir sua responsabilidade social, uma vez que somos sujeitos responsáveis em busca de uma formação que dialogue com o que se vive no chão da escola. Não podemos ficar confinadas em espaços ou ideias que nos reduzem e limitam. Podemos sair deste con.fi(n)ar partilhando saberes, experiências para que possam ser sentidas e vivenciadas por outros docentes para que outros coletivos se formem e possamos olhar para essa experiência singular com amorosidade.

Neste emaranhado de confiar, con.fiar e con.fi(n)ar, as narrativas foram alicerce para percorrer o caminho em tempos pandêmicos, porque, ao escrever, pudemos organizar os pensamentos, as dúvidas, as angústias, os desejos, os acertos e os erros vividos no chão da escola - que passou a ser a tela e/ou o espaço das nossas casas - para refletir as pró- 
prias escolhas e aprender com elas e com as que estavam sendo partilhadas entre pares. Acreditamos que neste percurso, encontramos abrigo nas palavras e nas relações vividas para ter uma travessia mais amena, com menor solidão e muita amorosidade, conectadas em fiar novas possibilidades de trabalho e reflexão.

\section{Referências}

AGUIAR, Thiago Borges; FERREIRA, Luciana Haddad. Paradigma indiciário: abordagem narrativa de investigação no contexto da formação docente. Educar em Revista, Curitiba, 2020. No prelo.

ARAGÃO, Ana Maria Falcão; FERREIRA, Luciana Haddad; PREZOTTO, Marissol. Imagens da docência: pensar a formação reflexiva do professor a partir das narrativas dos alunos. In: COSTA, Adriana Alves Fernandes; EVANGELISTA, Francisco; PRADO, Guilherme do Val. Narrativas que nos transformam: o que contam os educandos? São Carlos: Pedro \& João, 2017. p. 99-124.

BAKHTIN, Mikhail. Estética da criação verbal. São Paulo: Martins Fontes, 2000 (texto original de 1924).

BAKHTIN, Mikhail. Por uma filosofia do Ato Responsável. São Carlos: Pedro \& João Editores, 2010 (texto original de 1920-24).

BENJAMIN, Walter. Magia e técnica, arte e política: ensaios sobre literatura e história da cultura. Obras escolhidas I. São Paulo: Brasiliense, 1994 (texto original de 1940).

BENJAMIN, Walter. Passagens. Belo Horizonte: Editora UFMG, 2006 (textos originais de 1927-1940).

CERTEAU, Michael. A Invenção do cotidiano: 1. Artes de fazer. Petrópolis: Editora Vozes, 1994.

FERREIRA, Luciana Haddad. Educação estética e prática docente: exercício de sensibilidade e formação. 366p. Tese (Doutorado em Educação) FE, UNICAMP, Campinas, 2014. Disponivel em: <http://www.repositorio.unicamp.br/handle/REPOSIP/254170>. Acesso em: 1 jul. 2020.

FERREIRA, Luciana Haddad; BARBOSA, Andreza. Li- ções de quarentena: limites e possibilidades da atuação docente em época de isolamento social. Práxis Educativa, Ponta Grossa, v. 15, p. 1-24, 2020. Disponivel em: <https://www.revistas2.uepg.br/ index.php/praxiseducativa>. Acesso em: 21 jul. 2020.

FREIRE, Paulo. Educação como prática da liberdade. Rio de Janeiro: Paz e Terra, 1986.

FREIRE, Paulo. Pedagogia da Autonomia. Rio de Janeiro: Paz e Terra, 1997.

LIBÂNEO, José Carlos; OLIVEIRA, João Ferreira; TOSCHI, Mirsa Seabra. Educação escolar: políticas, estrutura e organização. São Paulo: Cortez, 2006.

NÓVOA, Antônio. Relação escola-sociedade: novas respostas para um velho problema. In: SERBINO, Raquel; RIBEIRO, Ricardo; BARBOSA, Raquel Lazzari (orgs.). Formação de Professores. São Paulo: Editora da UNESP, 1998. p. 19-40.

PRADO, Guilherme do Val; CHAUTZ, Grace Chaves Buldrin; PREZOTTO, Marissol; SERODIO, Liana Arrais; PROENÇA, Heloisa Martins. Uma narrativa de amorosidade: reflexões bakhtinianas a partir dos encontros dos sujeitos das e nas escolas. In: SANGENIS, Luiz Conde; OLIVEIRA, Elaine Rezende; CARREIRO Heloísa Santos (orgs). Formação de professores para uma educação plural e democrática: narrativas, saberes, práticas e políticas educativas na América Latina. Rio de Janeiro: EdUERJ, 2018. p. 77-98.

PREZOTTO, Marissol; FERREIRA, Luciana Haddad; ARAGÃO, Ana Maria Falcão. Sobre águas e meninos: formação de professores numa perspectiva histórico-cultural. Laplage em Revista, Sorocaba, v.1, 3, p.20-33, set./dez. 2015. Disponível em: https://www. laplageemrevista.ufscar.br/index.php/lpg/article/ view/98. Acesso em: 28 jun. 2020.

PREZOTTO, Marissol. 0 trabalho docente com.par. t(r)ilhado: focalizando a parceria. 229p. Tese (Doutorado em Educação). FE, UNICAMP, Campinas, 2015. Disponivel em: http://www.repositorio.unicamp.br/ handle/REPOSIP/254048>. Acesso em: 28 jun. 2020.

ROCHA, João; SÁ-CHAVES, Idália. Entrevista a especialista na área científica da Supervisão: professora Idália Sá-Chaves. Indagatio Didactia, Aveiros, v.4, 2, 
p.4-39, 2012. Disponivel em: https://www.researchgate.net/publication/321939202_Entrevista_a_Especialistas_na_area_cientifica_da_Supervisao_Professora_Idalia_SaChaves. Acesso em: 6 jul. 2020.

RUIVO, João. Avaliação de Desempenho de Professores. Castelo Branco: RVJ Editores, 2009.

TERRA, Juliana; ANTONIO, Cristiane Silva; PRADO, Guilherme Val. Pipoquinhas - Papo de Criança: saberes e sabores das narrativas pedagógicas. In: COSTA, Adriana Alves Fernandes; EVANGELISTA, Francisco; PRADO, Guilherme do Val. Narrativas que nos transformam: o que contam os educandos? São
Carlos: Pedro \& João, 2017. p.21-38.

VIGOTSKI, Lev Semenovich. A construção do Pensamento e da Linguagem. São Paulo: Martins Fontes, 2001 (texto original de 1934).

VIGOTSKI, Lev Semenovich. Sete aulas de L. S. Vigotski sobre os fundamentos da pedologia. Rio de Janeiro: E-Papers, 2018 (textos originais de 1927).

Recebido em: 28/07/2020

Revisado em: 15/12/2020

Aprovado em: 17/12/2020

Luciana Haddad Ferreira é doutora em Educação. Professora do Programa de Pós-Graduação em Educação da Universidade Metodista de Piracicaba (Unimep). Membro do Grupo de Estudos e Pesquisa em Educação Continuada (Gepec) da Universidade Estadual de Campinas (Unicamp).E-mail: haddad.nana@gmail.com

Marissol Prezotto é doutora em Educação. Professora do Instituto Brasileiro de Formação de Educadores (IBFE). Membro do Grupo de Estudos e Pesquisa em Educação Continuada (Gepec) da Universidade Estadual de Campinas (Unicamp).E-mail: marissol.prezotto@gmail.com

Juliana Terra é doutora em Química. Professora do Programa de Ensino Integral do Governo do Estado de São Paulo. Membro do Grupo de Estudos e Pesquisa em Educação Continuada (Gepec) da Universidade Estadual de Campinas (Unicamp).E-mail: juliterra@gmail.com 